\title{
Anatomical plating versus titanium elastic nailing for displaced midshaft clavicle fractures: a prospective comparative study
}

\author{
Ashish Philip ${ }^{1}$, Shishir Murugharaj Suranigi²*, Lingaraj ${ }^{3}$, \\ Kanagasabai Rengasamy ${ }^{3}$, Syed Najimudeen ${ }^{3}$
}

\begin{abstract}
${ }^{1}$ Department of Orthopaedics, Aster R.V. Hospital, Bangalore, Karnataka, India
${ }^{2}$ Department of Orthopaedics, Subbaiah Institute of Medical Sciences, Shivamogga, Karnataka, India

${ }^{3}$ Department of Orthopaedics, Pondicherry Institute of Medical Sciences, Pondicherry, India
\end{abstract}

Received: 03 December 2020

Accepted: 11 January 2021

*Correspondence:

Dr. Shishir Murugharaj Suranigi,

E-mail: shishir100@gmail.com

Copyright: () the author(s), publisher and licensee Medip Academy. This is an open-access article distributed under the terms of the Creative Commons Attribution Non-Commercial License, which permits unrestricted non-commercial use, distribution, and reproduction in any medium, provided the original work is properly cited.

\begin{abstract}
Background: Plate fixation has become the standard operative method for fixing displaced midshaft clavicle fractures. Over the years, TENS has also gained lot of attention due to its minimal invasive nature, smaller scar and reduced operative time. The purpose of this study was to compare the functional outcome of middle third displaced clavicle fractures treated either by plate or intra medullary TENS fixation using Constant Murley score and disability of the arm, shoulder and hand score.

Methods: A prospective randomised study was conducted from January 2010 to September 2016 at our institute on patients with displaced midshaft clavicle fractures. A total of 56 patients (TENS; $n=25$, plating; $n=31$ ), classified according to orthopaedic trauma association classification underwent midshaft clavicle fixation. They were followedup for a minimum period of 1 year.

Results: Length of the scar in the TENS group was significantly smaller when compared to the incision in the plating group (1.86 \pm 1.23 and $11.01 \pm 3.29 \mathrm{cms}$ respectively, $\mathrm{p}<0.001)$. The Constant shoulder score measured at the end of 1 year was $90.77 \pm 9.01$ for the TENS group and 92.63 \pm 6.04 for the plating group, not significant statistically ( $\mathrm{p}=0.269$ ). The mean DASH score was also not significantly different $(\mathrm{p}=0.552)$ between the TENS group and the plating group, at $6.01 \pm 11.09$ and $6.32 \pm 10.33$ respectively.

Conclusions: In comparison with plate fixation, the nailing procedure is less invasive, requires smaller incisions and has a shorter duration of hospital stay with no statistically significant difference in terms of functional outcome. Hence, TENS technique is recommended for the fixation of displaced mid-shaft non-/minimal comminuted clavicular fractures, especially for young individuals and can be used as an alternative to plate fixation.
\end{abstract}

Keywords: Middle one-third clavicle fractures, Clavicle plating, Intramedullary clavicle nailing, Titanium elastic nailing system

\section{INTRODUCTION}

Clavicle fractures comprise of $5-10 \%$ of all skeletal fractures, due to the unique shape and configuration of the clavicle, the central third is the weakest and accounts for $69.2 \%$ to $81.3 \%$ of fractured clavicles. ${ }^{1}$ Displaced midshaft fractures of the clavicle have traditionally been treated non-operatively, with the expectation that little functional loss will result despite substantial residual radiographic mal-alignment. However, many previous studies depended on surgeon or radiograph based outcome measures, which may not have detected subtle deficits. Although many methods have been described for closed reduction of displaced clavicular shaft fractures, none have been consistently reliable in achieving and maintaining reduction. Thus, displaced midshaft fractures of the 
clavicle typically heal in approximately the same position as that seen on initial radiographs, i.e. with a characteristic inferior, medially translated and anteriorly rotated deformity of the lateral fragment. ${ }^{2}$ More recent studies, over the last ten years, have demonstrated higher rates of non-union and poorer functional outcomes after nonoperative treatment, while the results of primary operative reduction and fixation have improved considerably. ${ }^{3,4}$

Since a satisfactory functional outcome may be obtained after operative treatment of a clavicular non-union or malunion, there is currently considerable debate about the benefits of primary operative treatment of these injuries. ${ }^{2,5}$ Various studies have shown that surgical management is increasing by using either plates or intra medullary nails for fixation. While plating has been the gold standard for surgical fixation of fractured middle third clavicle, the last decade has seen the emergence of intra medullary nailing as a good means of surgical fixation with better cosmetic outcome. $^{6-8}$

The purpose of this study was to compare the functional outcome for middle third displaced clavicle fracture treated either by anatomical plating or titanium elastic nailing system (TENS) fixation using Constant Murley score and disability of the arm, shoulder and hand (DASH) score..$^{9,10}$

\section{METHODS}

A prospective comparative study was conducted from January 2010 to September 2016 at our institution on patients with displaced midshaft clavicle fractures. Clavicle middle third fractures were classified as B1-type fractures (simple fractures, two fragments), B2-type fractures (fractures with bending wedge) and B3-type fracture (complex fractures) according to the classification of the orthopaedic trauma association (OTA). ${ }^{11}$

\section{Inclusion criteria}

Inclusion criteria for current study were; a markedly displaced midshaft clavicle fracture with skin tenting, shortening or over-riding of clavicle $>2 \mathrm{~cm}$ on radiographs, patients with multiple ipsilateral rib fractures with respiratory insufficiency, age of the patient more than 18 years with ability to provide complete information, sign a consent form, fill out questionnaires, and attend regular follow ups.

\section{Exclusion criteria}

Exclusion criteria for current study were; patients with floating shoulder, patients with bony injuries of ipsilateral upper limb or brachial plexus injury, bilateral clavicle fractures, pathologic fracture, open clavicle fractures, and clavicle fracture more than 2 weeks duration.

\section{Procedure}

The intra-operative complication observed consistently was the difficulty in manoeuvring the nail at the lateral end of the clavicle as it curves posteriorly and flattens out laterally. Opening the fracture site with a two centimetre incision and use of a towel clip/reduction forceps aided in smooth passage of nail laterally. All the cases were operated by the same surgical team to reduce the variations that may arise due to the surgical procedure and further alter the functional outcome of the study. All patients were operated under general anaesthesia in beach chair position. In the TENS group, a skin incision of $1 \mathrm{~cm}$ was made parallel to the clavicle. Under fluoroscopic guidance, the anterior cortex was opened with an awl about $1.5 \mathrm{~cm}$ lateral to the sterno-clavicular joint and a TENS $(2.5 \mathrm{~mm})$ which was mounted over a T-handle was inserted and advanced to the fracture site. The fracture was reduced in a closed manner. If closed reduction was not successful, a $2 \mathrm{~cm}$ skin incision at the level of the fracture site was made and the reduction was maintained provisionally with a small reduction forceps or towel clip. The nail was then advanced across the fracture into the lateral fragment with gentle rotational movements. The nail was then bent, cut and buried under the skin to prevent skin irritation. In the plating group, the fractured ends of the clavicle were open reduced using the anterior approach and fixed with a 3.5 $\mathrm{mm}$ anatomical locking plate (Sharma surgicals) applied in superior position. Bone grafting was done in cases of severe communition.

After surgery, all patients (TENS and plating group) were put on an arm sling. All patients were started on early gentle and passive shoulder mobilization exercises from the second post-operative day to a period of 3 weeks. Check X-ray was advised 3 weeks post-surgery to assess for alignment. Active mobilisation was started 3 weeks after surgery. Arm sling was discontinued after 6 weeks and over-head range of motion was initiated. In patients with simple fractures, active shoulder range of motion was permitted 2 weeks after surgery. Regular postoperative follow up was performed at 2 weeks, 6 weeks, and then monthly. At the end of one-year post operation, we assessed bilateral clavicle length difference for clavicle shortening (from the notch of the sternum to the ridge of the acromion, functional status of the shoulder using the constant and Murley shoulder scores and the disability of the arm, shoulder, and hand score.

Variables such as age, sex, side of fracture and fracture type were compared between the TENS and plating groups using Fisher's exact test. The functional outcomes and complications for the two groups were compared using the independent ' $t$ ' test. The Constant score, DASH score, and post-operative clavicle length shortening were compared using analysis of variance (ANOVA). All statistical comparisons were made using SPSS version 20.0. 


\section{RESULTS}

A total of 56 patients underwent midshaft clavicle fixation either with TENS or anatomical locking plate. All patients had a minimum follow up of 1 year. Out of the 56 patients, 31 of them underwent nailing and 25 underwent plating. The mean age of patients in the nailing group was 34.5 years (18-55 years) compared to 36.5 years (18-58 years) in the plating group. The mode of injury was studied with the type of fracture pattern to see if there was any significance between the two groups. Road traffic accident was the most common aetiology in both the groups; total $=38(67.86 \%) ; \mathrm{n}=20$ (nailing) and $\mathrm{n}=18$ (plating). Among which $47 \%(\mathrm{n}=18)$ were simple, $21.1 \%(\mathrm{n}=8)$ were wedge and $31.60 \%(n=12)$ were communited fractures. Fall from height accounted for 11 cases $(19.64 \%)$ and 7 cases $(12.5 \%)$ were due to direct blow on the clavicle. 18 patients in the TENS group and 12 patients in the plating group had OTA 15-B1 non-comminuted fracture type, classified as a simple fracture. 5 patients in the TENS group and 3 patients in the plating group had 15-B2 wedge comminuted fracture type. 8 patients in the TENS group and 10 patients in the plating group had 15-B2 wedge comminuted fracture type (Table 1).

Table 1: Demographic data of patients.

\begin{tabular}{|c|c|c|c|}
\hline & $\begin{array}{l}\text { TENS } \\
(\mathrm{n}=31)\end{array}$ & $\begin{array}{l}\text { Plating } \\
(\mathrm{n}=25)\end{array}$ & $P$ value \\
\hline Age (years) & $34.5(18-55)$ & $36.5(18-58)$ & 0.067 \\
\hline \multicolumn{4}{|l|}{ Sex } \\
\hline Male & 22 & 17 & \multirow{3}{*}{0.456} \\
\hline Female & 09 & 08 & \\
\hline Total & 31 & 25 & \\
\hline \multicolumn{4}{|c|}{ Fracture type (OTA) } \\
\hline Type B1 & 18 & 12 & \multirow{3}{*}{0.269} \\
\hline Type B2 & 05 & 03 & \\
\hline Type B3 & 08 & 10 & \\
\hline \multicolumn{4}{|c|}{ Side affected } \\
\hline Left & 21 & 13 & \multirow{2}{*}{0.091} \\
\hline Right & 10 & 12 & \\
\hline
\end{tabular}

Out of the 31 patients who underwent nailing, 15 (4-B1, 2$\mathrm{B} 2$ and 9-B3) of them needed open reduction in the form of $2 \mathrm{~cm}$ incision at the fracture site to aid in passage of the TENS, suggesting that communition was the deciding factor for open reduction. In such cases the length of the scar was calculated by adding the nail entry site and the fracture site scar. The average duration of hospital stay was $4.13 \pm 2.38$ days for nailing group as compared to $7.24 \pm 4.10$ days for plating group $(\mathrm{p}=0.001)$. The mean surgical wound size was $1.86 \pm 1.23 \mathrm{cms}$ in the TENS group compared to $11.01 \pm 3.29 \mathrm{cms}$ in the plating group. The TENS group had a significantly smaller wound size than the plating group $(\mathrm{p}<0.001)$. The mean clavicle shortening after union was significant in the TENS group as compared to the plating group $(0.76 \pm 0.93$ and $0.09 \pm 0.29 \mathrm{cms}$ respectively; $p=0.044$ ) (Figure 1). Length of the scar in the TENS group was also significantly smaller when compared to the incision in the plating group $(1.86 \pm 1.23$ and $11.01 \pm 3.29 \mathrm{cms}$ respectively; $\mathrm{p}<0.001)$. Five patients (4 female, 1 male) in the plating group developed heterotrophic scar formation compared to 1 patient (female) in the TENS group $(\mathrm{p}=0.046)$. There was no significant difference in the average union duration in both the groups, $(10.17 \pm 1.84$ and $10.88 \pm 2.44$ weeks respectively, $\mathrm{p}=0.430$ ) (Figure 2 and 3 ). The constant shoulder score measured at the end of 1 year was $90.77 \pm 9.01$ for the TENS group and $92.63 \pm 6.04$ for the plating group, not significant statistically $(\mathrm{p}=0.269)$. The mean DASH score was also not significantly different $(p=0.552)$ between the TENS group and the plating group, at $6.01 \pm 11.09$ and $6.32 \pm 10.33$ respectively (Table 2 ).

Table 2: Results of varied parameters.

\begin{tabular}{|c|c|c|c|}
\hline Parameters & $\begin{array}{l}\text { TENS } \\
(n=31)\end{array}$ & $\begin{array}{l}\text { Plating } \\
(\mathbf{n}=25)\end{array}$ & P value \\
\hline $\begin{array}{l}\text { Duration of hospital } \\
\text { stay (days) }\end{array}$ & $\begin{array}{l}4.13 \\
\pm 2.38\end{array}$ & $\begin{array}{l}7.24 \\
\pm 4.10\end{array}$ & 0.001 \\
\hline $\begin{array}{l}\text { Clavicle shortening } \\
(\mathrm{cm})\end{array}$ & $\begin{array}{l}0.76 \\
\pm 0.93\end{array}$ & $\begin{array}{l}0.09 \\
\pm 0.29\end{array}$ & 0.044 \\
\hline Scar length (cms) & $\begin{array}{l}1.86 \\
\pm 1.23\end{array}$ & $\begin{array}{l}11.01 \\
\pm 3.29\end{array}$ & $<0.001$ \\
\hline $\begin{array}{l}\text { Average union time } \\
\text { (weeks) }\end{array}$ & $\begin{array}{l}10.17 \\
\pm 1.84 \\
\end{array}$ & $\begin{array}{l}10.88 \\
\pm 2.44 \\
\end{array}$ & 0.430 \\
\hline Constant score & $\begin{array}{l}90.77 \\
\pm 9.01 \\
\end{array}$ & $\begin{array}{l}92.63 \\
\pm 6.04\end{array}$ & 0.269 \\
\hline DASH score & $\begin{array}{l}6.01 \\
\pm 11.09\end{array}$ & $\begin{array}{l}6.32 \\
\pm 10.33\end{array}$ & 0.552 \\
\hline
\end{tabular}

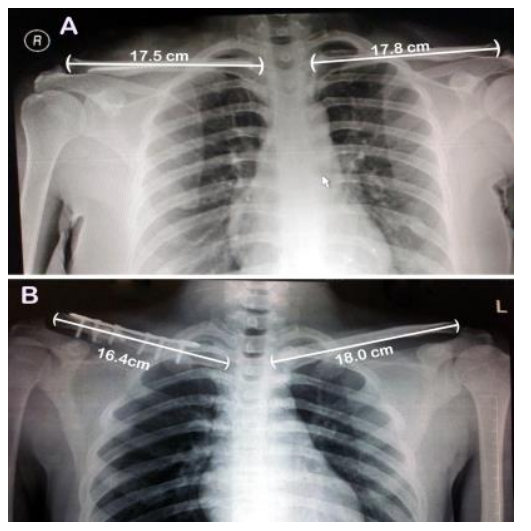

Figure 1: Measuring the clavicle shortening after union A) Post-TENS fixation, B) Post-anatomical plating.

There were total of 5 superficial infections ( 2 in TENS group and 3 in plating group) and 1 deep infection in the plating group. All the superficial infections were treated with systemic antibiotics ranging from 7-10 days. One patient in the plating group developed deep infection during the follow-up period. Wound debridement and implant removal was performed at 6 weeks post-operative period. After 15 days of systemic antibiotic treatment the fracture mal-united without any further complications. Patient had a good functional outcome with a final constant 
score of 90.45 at the end of 1 year. Another patient, a 40year-old male presented to us with plate exposure following superficial infection at 3 months of follow-up. Fracture had united. Hence, he underwent debridement, plate removal and primary closure under the cover of a drain. Wound subsequently healed without any further complications. One patient in the plating group had implant failure due to re-injury to the operated clavicle while travelling in a public transport bus when the driver braked suddenly. Implant exit was done and re-fixation was done with a new locking anatomical $S$ plate with additional bone grafting done to fill the defect and fasten healing (Figure 4).

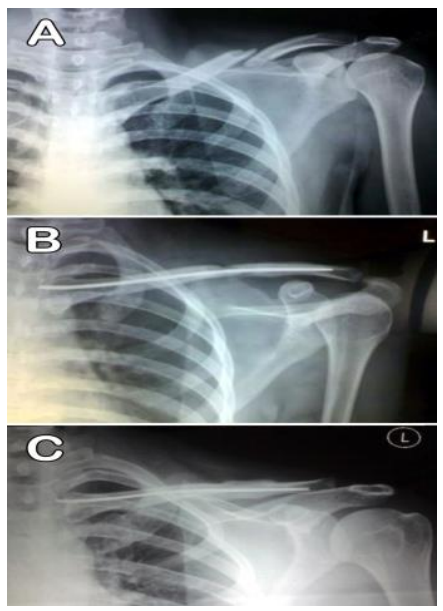

Figure 2: A) Radiograph of a 24 year old male with left sided middle third simple clavicle fracture (OTA classification B1), B) immediate post-operative radiograph showing acceptable reduction with TENS in-situ, C) radiograph of the clavicle showing good union at the fracture site after 3 months postoperative follow-up.

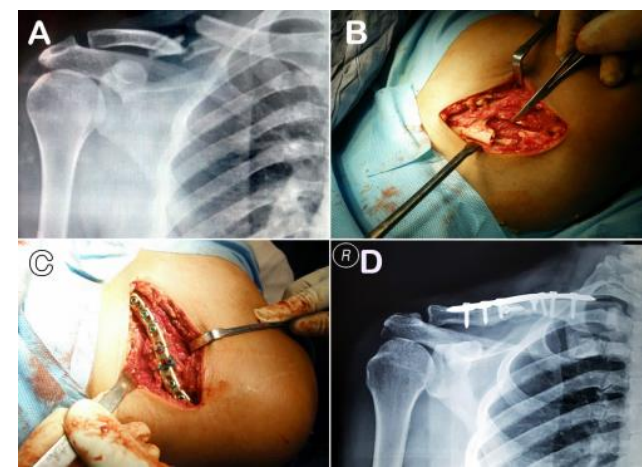

Figure 3: A) Radiograph of a 34 year old male with right sided middle third comminuted clavicle fracture (OTA classification B3), B) Intra-operative image of the segmental comminution, $C$ ) Intra-operative image

post plating with inter-fragmentary screws and adequate bone grafting at the fracture site. Note the iliac cortico-cancellous grafts tied at the fracture site with the help of ethibond sutures for better integration, D) Post-operative radiograph showing the good union of the fracture at 3 months of follow-up.

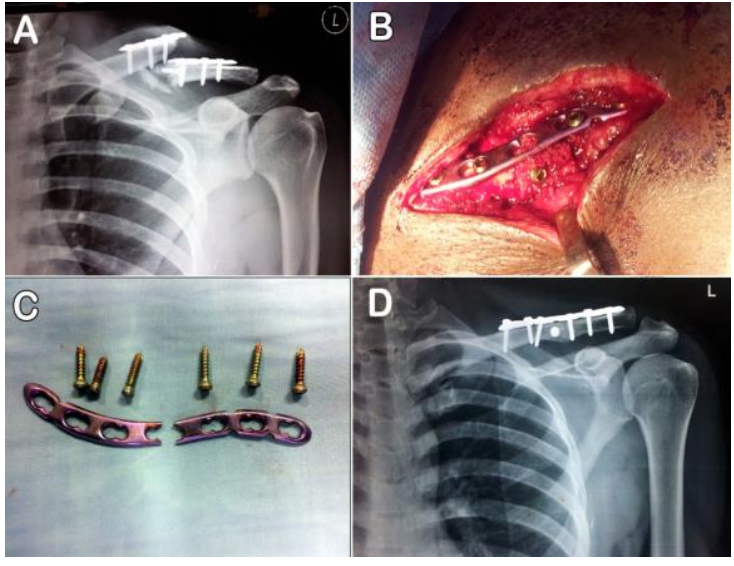

Figure 4: A) Post-traumatic radiograph of a 31 year old male with left sided middle third comminuted clavicle fracture (OTA classification B3), initially treated with plating; now with re-fracture at the fracture site with plate breakage, B) Intra-operative image of re-fixation of the fracture with tri-cortical bone graft fixed with a screw to fill the defect, $\mathrm{C}$ ) Photograph of the removed broken implant with screws, D) Post-operative radiograph showing the good union of the fracture at $\mathbf{4}$ months of follow-up.

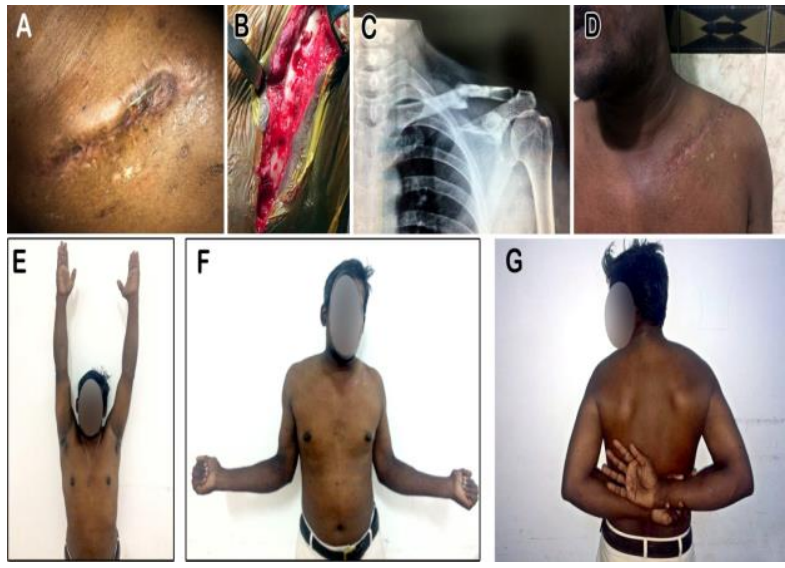

Figure 5: A) A 26 year old male who developed minimal discharge from the surgical site 8 weeks postsurgery, B) Intra-operative photograph showing fibrous union at the fracture with significant osteolysis around the screw holes, C) Radiograph showed non-union at the fracture site post implant exit, D) Healed surgical site post debridement and implant exit, E-F-G) Clinical images of the patient depicting pain-free full range of motion at the shoulder joint.

Among the 56 patients who were questioned about the implant prominence, 7 patients in the TENS group and 6 in the plating group expressed their concerns about the implant being prominent. One patient in the TENS group required trimming of the medial end of the nail under local anaesthesia in the out-patient department as patient complained about significant prominence and skin irritation. Three patients in the plating group complained 
about loss of sensation over the clavicle as compared to one patient in the TENS group. One patient in each group ended in non-union. Both the patients had 15-B3 fracture pattern. The patient in the plating group complained of minimal discharge from the surgical site 8 weeks postsurgery. Intra-operative deep cultures suggested acinetobacter baumannii growth. Debridement and implant exit was done. Subsequent infection subsided with antibiotics and radiographs showed non-union at the fracture site. There was no abnormal mobility at the fracture site noted clinically after the implant exit. Functionally, patient had pain-free full range of motion at the shoulder joint (Figure 5). Whereas, the patient with the non-union in the nailing group underwent revision surgery with plate and bone grafting at 4 months follow-up. The fracture subsequently united after 3 months without any further complications. Malunion was defined as angulation more than 10 degrees in antero-posterior radiograph (Figure 6). We observed asymptomatic mal-union in 2 of the 31 patients. Both had superiorly angulated union. Most of the TENS (29 out of 31) were removed at a mean follow-up of 6.56 months (range: 6 to 9 months). Plate removal was not routinely recommended for the patients but 5 of them requested for implant exit (Table 3 ). The mean follow-up for these 5 patients was 12.5 months (range: 10 months to 15 months).

Table 3: Complications.

\begin{tabular}{|llll|}
\hline & $\begin{array}{l}\text { TENS } \\
(\mathbf{n = 3 1})\end{array}$ & $\begin{array}{l}\text { Plating } \\
(\mathbf{n = 2 5})\end{array}$ & $\begin{array}{l}\text { P } \\
\text { value }\end{array}$ \\
\hline Infection & & & \\
\hline Superficial & 2 & 3 & 0.345 \\
\hline Deep & 0 & 1 & 0.455 \\
\hline Implant failure & 0 & 1 & 0.121 \\
\hline $\begin{array}{l}\text { Implant prominence } \\
\text { (subjective) }\end{array}$ & 7 & 6 & 0.784 \\
\hline Skin irritation & 4 & 5 & 0.078 \\
\hline $\begin{array}{l}\text { Loss of sensation } \\
\text { over the clavicle }\end{array}$ & 1 & 3 & 0.471 \\
\hline Non-union & 1 & 1 & 0.587 \\
\hline $\begin{array}{l}\text { Heterotrophic scar } \\
\text { formation }\end{array}$ & 1 & 5 & $0.046^{*}$ \\
\hline Malunion & 2 & 1 & 0.060 \\
\hline Implant exit & 29 & 5 & $0.007 *$ \\
\hline $\begin{array}{l}\text { Re-fracture after } \\
\text { implant exit }\end{array}$ & 0 & 0 & 0.899 \\
\hline *tatistically significant $(\mathrm{p}<0.05)$. & & \\
\hline
\end{tabular}

\section{DISCUSSION}

Clavicle fractures are still treated conservatively with good functional and radiological outcomes. Although the indications for surgical fixation of midshaft clavicle fractures remain controversial, they appear to be increasing. Eighty percent of all clavicle fractures involve the middle third of the clavicle. ${ }^{12}$ Due to the increasing dissatisfaction among patients treated conservatively, following a clavicle malunion, especially with overhead work, more and more trauma surgeons are exploring the different options of surgical fixation. Plate fixation has become the standard operative method for fixing displaced midshaft clavicle fractures. ${ }^{13}$ Over the years, TENS has also gained lot of attention due to its minimal invasive nature, smaller scar and reduced operative time. ${ }^{14}$ Our study demonstrated that intramedullary TENS fixation had comparable clinical results to plate fixation of displaced midshaft clavicle fractures. No significant difference was found in the constant shoulder score $(p=0.269)$ or DASH $(p=0.552)$ scores between the TENS and plating groups. Literature suggests that the displaced fracture site and the S-shape anatomy of the clavicle needs larger incision to accommodate the plate on to the bone. ${ }^{15}$ In our study, the TENS group had significantly smaller scar length $(1.86 \pm 1.23 \mathrm{cms})$ compared to plating group $(11.01 \pm 3.29$ $\mathrm{cms}$ ) indicating that TENS fixation was far less surgically invasive than plate fixation $(\mathrm{p}<0.001)$. The TENS results in lesser soft tissue stripping, lesser blood loss, shorter operative time, and better cosmetic results than with traditional plate fixation as demonstrated in our study.
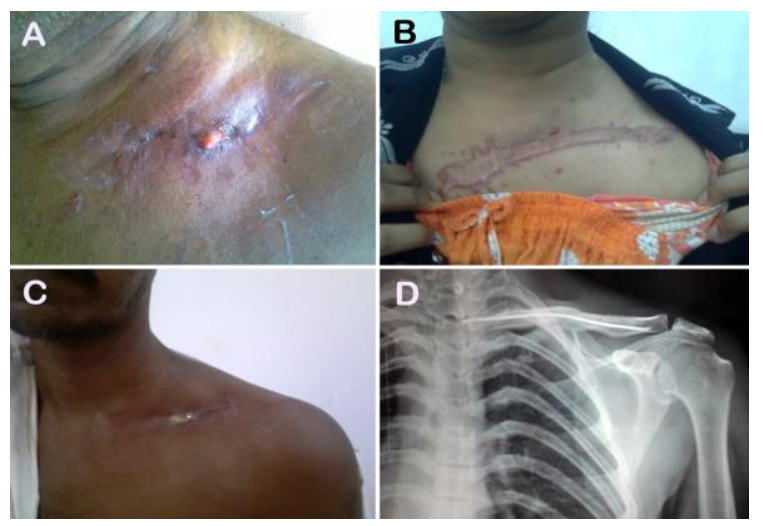

Figure 6: Complications, A) 68 year old uncontrolled diabetic patient with pus discharge from the operative site 3 weeks post-surgery. B) A 33 year old lady who developed hypertrophic scar at the surgical site after plate fixation for middle third clavicle fracture, C) $\mathrm{A}$ 40 year old patient with plate exposure following infection, D) Malunion following TENS.

The most commonly reported complications in plate fixation of clavicle fractures are related to the hardware and the large operative wound, including infectionssuperficial and deep, implant prominence, non-union, and poor cosmetic appearance. ${ }^{16}$ In our study, we had 3 superficial and 1 deep infection in the plating group as compared to 2 superficial infection in the TENS group. Recent studies show high patient satisfaction rates, good shoulder function and radiological results after using the intramedullary TENS for clavicle fracture fixation. ${ }^{17-19} \mathrm{We}$ had 2 cases of asymptomatic radiological malunion in the TENS group compared to one case in plating group which occurred due to removal of infected plate as described before. In a biomechanical study done by Zeng et al to compare TENS with plating for midshaft clavicle fixation, they concluded that TENS is generally preferable for 
treating simple displaced fractures of the midshaft clavicle, because it showed a stress distribution similar to that of an intact clavicle. However, TENS provided lesser stability as compared to plating. They suggested that excessive exercise and weight bearing on the ipsilateral shoulder should be avoided in the early postoperative period to prevent failure. They further stated that, fixation with a reconstruction plate was more stable than TENS but showed stress shielding. They concluded that plate fixation was preferred in patients who demanded early return to activity. ${ }^{20}$

Recently studies emphasize the importance of preserving clavicle length after midshaft clavicle fractures in order to achieve excellent shoulder functional results. Many authors have stated that clavicle shortening may lead to limitations in overhead motion, pain, and weakness of the shoulder girdle due to increase in the sterno-clavicle joint angle, a change in the resting position of the scapula and an increase in the preload stress on the muscles of the shoulder girdle. ${ }^{21-23}$ Schultz et al reported an $8 \%$ decrease in shoulder external rotation strength and an $11 \%$ loss of shoulder abduction endurance strength in patients with significant shortening of the mal-united clavicle fractures treated conservatively. ${ }^{24}$ Lazarides and Zafiropoulos concluded that final clavicle shortening of $>18 \mathrm{~mm}$ in male patients and $>14 \mathrm{~mm}$ in female patients would significantly affect the motion at the shoulder girdle. ${ }^{25}$ Patients with $>2 \mathrm{~cm}$ of clavicle shortening had a DASH score of $>30$ points when compared with those with $<2 \mathrm{~cm}$ of shortening in a study conducted by McKee et al. They suggested that to have a good shoulder girdle motion, it was important to achieve a union with $<2 \mathrm{~cm}$ of shortening. After this critical threshold, poor functional outcomes increases dramatically. ${ }^{26}$

Further literature review suggests that plate fixation can provide more rigid stabilization than intramedullary pin fixation does, and may help facilitate early mobilization and offer a superior construct for highly comminuted fractures. However, this technique may require large incisions and extensive exposure, which could cause complications such as infection, scarring, and re-fracture after the removal of the plate. ${ }^{16,27-30}$ There were no cases of re-fracture after removal of implant reported in either of the groups in our study.

\section{CONCLUSION}

Both intramedullary TENS and anatomically contoured clavicle plates are reasonable choices for fixation of midshaft clavicle fractures. The less invasive technique of intramedullary TENS fixation may have improved early results with shorter operative times and faster overall fracture healing, but in the long term evaluation there was no significant difference in overall rate of union and achievement of full shoulder motion between the two groups. The higher rate of implant failure associated with TENS fixation may indicate that this implant is not suitable for all fracture patterns. We recommend plate fixation for fractures with significant comminution or a fracture with a large butterfly fragment. TENS fixation should be reserved for simple fractures or with minimal communition with good cortical apposition as this technique is both more technically challenging and requires adequate bone purchase thus making it less suitable for rotationally and axially unstable fracture patterns.

\section{ACKNOWLEDGEMENTS}

Authors are thankful to Mr. Ravichandran, Lecturer, department of biostatistics, Pondicherry institute of medical sciences for helping in analysing the data statistically.

Funding: No funding sources

Conflict of interest: None declared

Ethical approval: The study was approved by the institutional ethics committee

\section{REFERENCES}

1. Schiffer G, Faymonville C, Skouras E, Andermahr J, Jubel A . Midclavicular fracture:not just a trivial injury. Dtsch Arztebl Int. 2010;107(41):711-7.

2. Hill JM, Mcguire MH, Crosby LA. Closed treatment of displaced middle third fractures of the clavicle gives poor results. J Bone Joint Surg Br. 1997;79(4): 537-9.

3. Houwert RM, Wijdicks FJ, Steins Bisschop C, Verleisdonk EJ, Kruyt M. Plate fixation versus intramedullary fixation for displaced mid-shaft clavicle fractures: a systematic review. Int Orthop. 2012;36(3):579-85.

4. Assobhi JE. Reconstruction plate versus minimal invasive retrograde titanium elastic nail fixation for displaced midclavicular fractures. J Orthop Traumatol. 2011;12(4):185-92.

5. Van der Meijden OA, Gaskill TR, Millett PJ. Treatment of clavicle fractures: current concepts review. J Shoulder Elbow Surg. 2012;21(3):423-9.

6. Kettler M, Schieker M, Braunstein V, Konig M, Mutschler W. Flexible intramedullary nailing for stabilization of displaced midshaft clavicle fractures: technique and results in 87 patients. Acta Orthop. 2007;78(3):424-9.

7. Strauss EJ, Egol KA, France MA, Koval KJ, Zuckerman JD. Complications of intramedullary Hagie pin fixation for acute midshaft clavicle fractures. J Shoulder Elbow Surg. 2007;16(3):280-4.

8. Frigg A, Rillmann P, Perren T, Gerber M, Ryf C. Intramedullary nailing of clavicular midshaft fractures with the titanium elastic nail: problems and complications. Am J Sports Med. 2009;37(2):352-9.

9. Constant CR, Murley AH. A clinical method of functional assessment of the shoulder. Clin Orthop Relat Res. 1987;214(1):160-4.

10. Hudak PL, Amadio PC, Bombardier C. Development of an upper extremity outcome measure: the DASH, 
the upper extremity collaborative group. Am J Ind Med. 1996;29(6):602-8.

11. Shishir SM, Lingaraj, Ashish PZ, Kanagasabai R, Syed N, James JG. Antegrade flexible intramedullary nailing for fixation of displaced midshaft clavicle fractures. IOSR J Dent Med Sci. 2014;13(4):29-37.

12. Verborgt O, Pittoors K, Van Glabbeek F, Declercq G, Nuyts R, Somville J. Plate fixation of middle-third fractures of the clavicle in the semi-professional athlete. Acta Orthop Belg. 2005;71(1):17-21.

13. Wijdicks FJ, Van der Meijden OA, Millett PJ, Verleisdonk EJ, Houwert RM. Systematic review of the complications of plate fixation of clavicle fractures. Arch Orthop Trauma Surg. 2012;132(5):617-25.

14. Liu PC, Chien SH, Chen JC, Hsieh CH, Chou PH, Lu CC. Minimally invasive fixation of displaced midclavicular fractures with titanium elastic nails. J Orthop Trauma. 2010;24(4):217-23.

15. Kleweno CP, Jawa A, Wells JH, O’Brien TG, Higgins LD, Harris MB, et al. Midshaft clavicular fractures: comparison of intramedullary pin and plate fixation. $\mathbf{J}$ Shoulder Elbow Surg Am. 2011;20(7): 1114-7.

16. Böhme J, Bonk A, Bacher G, Wilharm A, Hoffmann R, Josten C. Current treatment concepts for mid-shaft fractures of the clavicle-results of a prospective multicentre study. Z Orthop Unfall. 2011;149(1):68-76.

17. Chen YF, Wei HF, Zhang C, Zeng BF, Zhang CQ, Xue JF, et al. Retrospective comparison of titanium elastic nail (TEN) and reconstruction plate repair of displaced midshaft clavicular fractures. J Shoulder Elbow Surg. 2012;21(4):495-501.

18. Golish SR, Oliviero JA, Francke EI, Miller MD. A biomechanical study of plate versus intramedullary devices for midshaft clavicle fixation. J Orthop Surg Res. 2008;90(11):1495-8

19. Wang J, Meng XH, Guo ZM, Wu YH, Zhao JG. Interventions for treating displaced midshaft clavicular fractures: a Bayesian network metaanalysis of randomized controlled trials. Medicine. 2015;94(11):e595.

20. Zeng L, Wei H, Liu Y, Zhang W, Pan Y, Zhang W, et al. Titanium elastic nail (TEN) versus reconstruction plate repair of midshaft clavicular fractures: A finite element study. PLoS One. 2015;10 (5):126-31.
21. McKee MD, Wild LM, Schemitsch EH. Midshaft malunions of the clavicle. J Bone joint Surg Am. 2003;85(5):790-7.

22. Ledger M, Leeks N, Ackland T, Wang A. Short malunions of the clavicle: an anatomic and functional study. J Shoulder Elbow Surg. 2005;14 (4):349-54.

23. Nowak J, Holgersson M, Larsson S. Sequelae from clavicular fractures are common: a prospective study of 222 patients. Acta Orthop. 2005;76(4):496-502.

24. Schulz J, Moor M, Roocroft J, Bastrom TP, Pennock AT. Functional and radiographic outcomes of nonoperative treatment of displaced adolescent clavicle fractures. J Bone Joint Surg Am. 2013;95(13):1159-65.

25. Lazarides $S$, Zafiropoulos G. Conservative treatment of fractures at the middle third of the clavicle: the relevance of shortening and clinical outcome. J Shoulder Elbow Surg. 2006;15(2):191-4.

26. McKee MD, Pedersen EM, Jones C, Stephen DJ, Kreder HJ, Schemitsch EH, et al. Deficits following nonoperative treatment of displaced midshaft clavicular fractures. J Bone Joint Surg Am. 2006;88(1):35-40.

27. Bostman O, Manninen M, Plihlajamak $H$. Complications of plate fixation in fresh, displaced midclavicular fractures. J Trauma. 1997;43(5):778-83.

28. Khan LA, Bradnock TJ, Scott C, Robinson CM. Fractures of the clavicle. Current concepts review. J Bone Joint Surg Am. 2009;91(2):447-60.

29. Van der Meijden OA, Gaskill TR, Millett PJ. Treatment of clavicle fractures: current concepts review. J Shoulder Elbow Surg. 2012;21(3):423-9.

30. Houwert RM, Wijdicks FJ, Steins Bisschop C, Verleisdonk EJ, Kruyt M. Plate fixation versus intramedullary fixation for displaced mid-shaft clavicle fractures: a systematic review. Int Orthop. 2012;36(3):579-85.

Cite this article as: Philip A, Suranigi SM, Lingaraj, Rengasamy K, Najimudeen S. Anatomical plating versus titanium elastic nailing for displaced midshaft clavicle fractures: a prospective comparative study. Int J Res Orthop 2021;7:278-84. 